\title{
Neonatal stimulation of the thyroid gland with iodine or suppression during adolescence with triiodothyronine changes the prevalence of autoimmune thyroiditis in $\mathrm{BB}$ rats
}

\author{
M-L Hartoft-Nielsen ${ }^{1,2}$, А K Rasmussen ${ }^{1}$, A Kaas ${ }^{2}$, U Feldt-Rasmussen ${ }^{1}$ and K Buschard ${ }^{2}$ \\ ${ }^{1}$ Department of Endocrinology PE-2131 and ${ }^{2}$ Bartholin Instituttet, Copenhagen University Hospital, Copenhagen, Denmark \\ (Correspondence should be addressed to M-L Hartoft-Nielsen, Department of Medical Endocrinology, Rigshospitalet, National University Hospital, \\ Blegdamsvej 9, DK-2100 Copenhagen, Denmark; Email: ma-lars@dadlnet.dk)
}

\begin{abstract}
Objective: Changes in the functional state of beta cells by neonatal stimulation or adolescent suppression have reduced the incidence of type 1 diabetes mellitus in animal models. The aim of this study was to evaluate the effect of manipulation of the activity of the thyroid gland by neonatal stimulation or by adolescent suppression on the prevalence of spontaneous autoimmune thyroiditis (AIT) in rats. Methods: Bio-Breeding/Worcester (BB) rats were treated neonatally with sodium iodine (NaI) or thyroid stimulating hormone (TSH), or during adolescence by triiodothyronine $\left(\mathrm{T}_{3}\right)$, and the lymphocytic infiltration in the thyroid gland was evaluated.

Results: Neonatal treatment with NaI decreased the prevalence of AIT to $32 \pm 9 \%$ compared with $66 \pm 5 \%$ in the controls $(P<0.002)$, mainly caused by a reduction among the female rats $(13 \pm 9 \%$ vs $52 \pm 8 \%, P<0.006)$. TSH had no effect. Post neonatal suppression of the thyroid gland by $\mathrm{T}_{3}$ had a biphasic response. Early in adolescence the overall prevalence was $14 \pm 7 \% \mathrm{com}$ pared with $66 \pm 5 \%$ in the controls $\left(P<10^{-5}\right)$; for female rats AIT was prevented $(0 \pm 0 \%)$ compared with $52 \pm 8 \%$ in the controls $(P<0.0003)$ and in male rats the values were $29 \pm 13 \%$ compared with $80 \pm 6 \%$ in the controls $(P<0.001)$. Treatment with $\mathrm{T}_{3}$ later in adolescence increased the overall prevalence to $81 \pm 7 \%$ compared with $66 \pm 5 \%$ in the controls (not significant). For female rats the prevalence increased to $78 \pm 9 \%$ compared with $52 \pm 8 \%$ in the controls $(P=0.04)$. The degree of thyroiditis among the affected animals was similar in all groups.

Conclusion: Neonatal stimulation of the thyroid gland by iodine or early adolescent suppression by $\mathrm{T}_{3}$ reduced the prevalence of AIT whereas $\mathrm{T}_{3}$ given later increased the prevalence of thyroiditis in rats. Thyroid activity at various ages seems to be of importance for the development of autoimmune thyroiditis.
\end{abstract}

European Journal of Endocrinology 151 375-382

\section{Introduction}

Autoimmune thyroiditis (AIT), including Graves' disease and Hashimoto's thyroiditis, best fits a polygenic, multifactorial model of disease in which genetically susceptible individuals are exposed to a constitutional or environmental insult resulting in activation of the immune system. AIT is characterized by lymphocytic infiltration of the thyroid gland, circulating autoantibodies against specific thyroid antigens, and an association between certain HLA-genes and development of Graves' disease and Hashimoto's thyroiditis (1, 2). The Bio-Breeding/Worcester (BB) rat develops spontaneous lymphocytic AIT and type 1 diabetes mellitus (T1DM) $(3,4)$. The thyroiditis in these rats is characterized by mononuclear cell infiltration in the thyroid gland but is not accompanied by any clinical signs of thyroid dysfunction or changes in serum concentrations of thyroid hormones (3).
An essential character of the immune system is 'self'-tolerance, which protects tissue antigens from damaging immune attacks. The functional state of an endocrine organ $(5-7)$ and the expression of antigenic determinants may be of importance in the pathogenesis of autoimmune diseases (8). It is known that autoimmunity is characterized by intolerance against 'self', that 'self' is established fetally and neonatally, and that antigen expression in endocrine organs is dependent on the functional stage of the organ. With this background we hypothesize that high antigen expression induces a stronger 'self' in the sense of difficulty in breaking tolerance resulting in less susceptibility to autoimmunity. Thus, a strong 'self' and high tolerance might be established neonatally by early increased organ activity. In contrast, later in life after the establishment of 'self', reduction of organ activity might impede break of tolerance. 
In humans, the influence of thyroid status on thyroid autoimmunity is controversial $(9,10)$. However, the comparable pathogenetic mechanisms of AIT and T1DM and the reduction in the incidence of T1DM by changed $\beta$-cell activity (11-13) caused us to examine whether changed thyroid activity (i.e. antigen expression) by neonatal stimulation with iodine or thyroid stimulating hormone (TSH), or adolescent suppression of the thyroid gland by triiodothyronine $\left(\mathrm{T}_{3}\right)$, could change the incidence of AIT in BB rats.

\section{Materials and methods}

$\mathrm{BB}$ rats of the subline NB were bred in our facility and were obtained originally from the University of Massachusetts, Worcester, MA, USA. The study consisted of two parts. In the first part, the influence of sodium iodine (NaI) and TSH administered neonatally on the prevalence and degree of AIT was evaluated at the age of 19 weeks. The influence of the chosen doses of $\mathrm{NaI}$ and TSH on serum thyroxine $\left(\mathrm{T}_{4}\right)$ levels at the age of 7 and 18 days, respectively, the day after the end of treatment, was also evaluated. In the second part, the influence of $\mathrm{T}_{3}$ administered during adolescence on the prevalence and degree of AIT was evaluated at the age of 19 weeks, and the effect of $\mathrm{T}_{3}$ on serum TSH levels the day after the end of treatment at the age of 9 weeks was evaluated.

All rats were kept in sterile stables under constant temperature, humidity and light/darkness cycle of 9/15 hours, respectively. All rats had free access to food and water. The animals were observed daily and examined twice a week for glucosuria (Test-Tape, Lilly, Indianapolis, IN, USA) after the age of 60 days. If positive for glusosuria, blood glucose was measured (Glucometer Elite, Bayer Diagnostics, Tokyo, Japan) and diabetes was diagnosed when blood glucose was $15 \mathrm{mmol} / \mathrm{l}$ and above. Diabetic rats were treated with 15-20 IU Insulatard (Novo Nordisk, Bagsværd, Denmark) every second day. At the age of 19 weeks the study was ended and the animals were killed. The study was ended at this age since many rats developed spontaneous diabetes and a total of 71 rats died because of dysregulated diabetes.

All rats were killed by breathing $70 \% \mathrm{CO}_{2}$. The animals were weighed and the thyroid gland was dissected out and placed in formalin. Blood was collected and serum was kept at $-20{ }^{\circ} \mathrm{C}$ for later analyses. To evaluate thyroid status in the rats at the time of death at the age of 19 weeks, 6 male rats with and 6 male rats without thyroiditis from each group of $\mathrm{BB}$ rats were randomly selected for measurement of TSH.

\section{Neonatal stimulation by NaI and TSH}

To stimulate the thyroid gland neonatally we chose to use iodine and TSH. NaI and TSH were administered by injection because the pups were fed by the mother and were unable to take treatment orally. Since treatment for 6 days with glucose is known to reduce the incidence of T1DM in BB rats and NOD mice $(11,12)$ we chose to give NaI (6523, Merck, Darmstadt, Germany) dissolved in sterile PBS and administered s.c. immediately post partum and daily for 6 days - $60 \mu \mathrm{g} \mathrm{NaI}$ daily for the first 3 days and $120 \mu \mathrm{g}$ for the last 3 days.

The plasma concentration of TSH is high neonatally (14) and since the hypothalamo-pituitary-thyroid axis changes dramatically in the neonatal period (15) TSH was administrated periodically for a longer period. TSH (T-3538, Sigma Chemical Co., St Louis, MO, USA) was dissolved in PBS and administered i.p. immediately post partum and daily for the first 3 days in each of the first 3 weeks - 0.5 IU per day for the first week and 1 IU per day for the first 3 days in the second and third weeks. Control groups were treated with corresponding medium only.

To evaluate the influence of the NaI and TSH treatment on the function of the thyroid gland, two groups of newborn BB rats bred in our facility and originating from Møllegaard, Lille Skensved, Denmark, were included and treated as described previously with $\mathrm{NaI}$ and TSH; two groups of rats served as control groups. All the rats in this part of the study were killed after the end of treatment at the age of 7 and 18 days, respectively, the day after end of treatment. Serum was collected and $\mathrm{T}_{4}$ was measured. The dose regimen of $\mathrm{NaI}$ insignificantly increased serum $\mathrm{T}_{4}$ to $48.5 \pm 2.6$ (mean \pm S.E.M.) from $42.6 \pm 1.3 \mathrm{nmol} / \mathrm{l}$. The dose regimen of $\mathrm{TSH}$ did not increase $\mathrm{T}_{4} \quad(44.1 \pm 2.9$ compared with $44.6 \pm 1.3 \mathrm{nmol} / \mathrm{l}$ in controls) while an increase has been shown for lower doses of TSH in rats (15). The doses were chosen to avoid thyrotoxicosis or tissue damage induced by the drug itself and after 3 days of treatment the doses were adapted to the increased bodyweight of the rats.

\section{Adolescent suppression by $\boldsymbol{T}_{3}$}

$\mathrm{T}_{3}$ for suppression was administered in the drinking water. This avoided stressing the rats by repeated injections and since it was present continuously, it may eliminate fluctuating serum levels. Since the timing for this suppression is important, we started the treatment at two different times. Two groups of BB rats were given $\mathrm{T}_{3}$ (T-2752, Sigma Chemical Co., dissolved in $0.5 \mathrm{ml} 1 \mathrm{M} \mathrm{NaOH}$ per $\mathrm{mg} \mathrm{T}_{3}$ ) which was administered daily in the drinking water from the age of either 3 to 9 weeks or 5 to 9 weeks at a concentration of $0.3 \mathrm{mg} / \mathrm{l}$ in the first 2 weeks and thereafter at a concentration of $0.2 \mathrm{mg} / \mathrm{l}$ corresponding to a daily dose of approximately 3-8 $\mu \mathrm{g}$. The control group received tap water. In Wistar rats, which do not develop AIT, the chosen dose regimen of $\mathrm{T}_{3}$ given from the age of 5 to 9 weeks suppressed TSH to $2.8(1.7-4.3)$ (median and range) compared with $4.1(3.3-5.7) \mathrm{mU} / \mathrm{l}$ in untreated controls $(P=0.03)$ immediately after the end of treatment at the age of 9 weeks, an effect that 

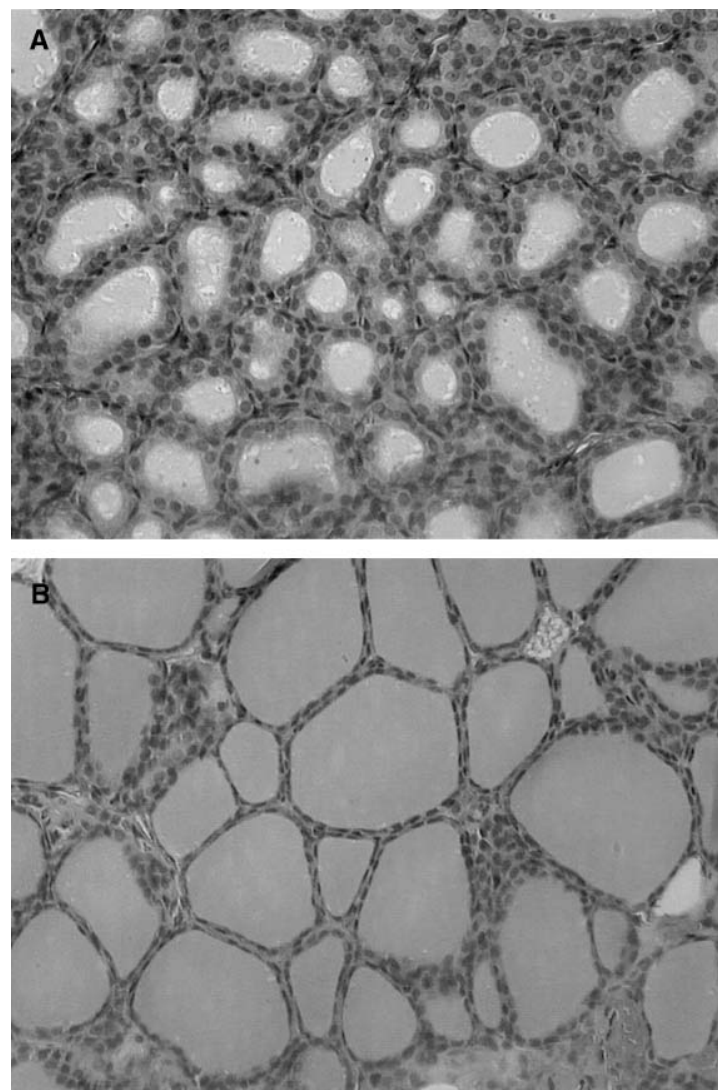

Figure 1 Thyroid glands from Wistar rats at the age of 9 weeks (A) Thyroid from untreated rat. (B) Thyroid in resting state from a Wistar rat treated with $T_{3}$ in the drinking water from the age of 5 to 9 weeks and killed just after the end of treatment. The final magnification was 620 .

disappeared within 3 weeks after the end of treatment $(4.7(4.4-8.3) \mu \mathrm{g} / \mathrm{l}$ and $3.9(2.5-5.7) \mu \mathrm{g} / \mathrm{l}$ respectively). The body weight of male Wistar rats treated with $\mathrm{T}_{3}$ was lower than in the control group $(275 \pm 5$ vs $304 \pm 7 \mathrm{~g}$ (mean \pm s.E.M.), $P<0.005)$ just after the end of treatment. This difference was not found 3 weeks after the end of treatment. The dose was chosen so as not to induce thyrotoxicosis. $\mathrm{T}_{3}$ in the given dose induced a resting state in the thyroid gland as evaluated by light microscopy on hematoxylin and eosin (HE)-stained sections (Fig. 1).

\section{$T_{4}$ measurement}

$\mathrm{T}_{4}$ was measured by Coat-A-Count Canine $\mathrm{T} 4$ assay (TKC41, Diagnostic Products Corporation, Los Angeles, CA, USA). The sensitivity was $2.1 \mathrm{nmol} / \mathrm{l}$, the intraassay variation was less than $4.3 \%$ at the level of our samples and the reference range was $18-50 \mathrm{nmol} / \mathrm{l}$.

\section{TSH measurement}

TSH was measured by the Amersham Pharmacia Biotech Rat TSH enzyme immunoassay system (code
RPN 2564, Amersham Pharmacia Biotech, UK Limited). The sensitivity was $0.6 \mu \mathrm{g} / \mathrm{l}$. The within-assay coefficient of variation was less than $6 \%$ and the reference range was 3-30 $\mu \mathrm{g} / \mathrm{l}$.

\section{Histopathological evaluation}

After killing at the age of 19 weeks the thyroid glands were dissected out, together with the trachea, and placed in formalin. Randomly rotated, assuming isotopic tissue destruction by autoimmune processes, the thyroids were embedded in paraffin, cut into $5 \mu \mathrm{m} \mathrm{sec-}$ tions and stained with HE. On average 12 (range 4 to 26) sections from each gland were randomly taken at different levels throughout the thyroid gland from each animal and were examined by two examiners who were unaware of the treatment groups for mononuclear cell infiltration and follicle disruption. A Leitz Leica Dialux $20 \mathrm{~EB}$ microscope was used with objectives of $2.5,10$ and 40 . On each section the extent of infiltration and tissue damage was estimated as a percentage and the final score for each gland was the mean of all the estimates. Finally, the degree of thyroiditis for each gland was expressed on a scale from 0 to 4 as previously described $(16,17)$ depending on the percentage of histological alteration related to the tissue area without knowledge of eventual tissue shrinkage: 0, normal histology; 1 , less than $10 \% ; 2$ approximately $10-30 \%$; 3, approximately $30-50 \%$; 4 , more than $50 \%$ (Fig. 2).

The thyroids from the rats killed at the age of 7 and 18 days respectively did not show any signs of necrosis or other toxic effects or thyroiditis on HE-stained sections evaluated by light microscopy compared with the corresponding control groups. It was not possible to detect cell stimulation or cell proliferation on the HE-stained sections evaluated by light microscopy.

\section{Ethics}

The study complies with the European Committee guidelines for the use of experimental animals and was approved by the local Ethical Committee.

\section{Statistics}

Unless otherwise stated the results are presented as means \pm S.E.M. Serum levels of $\mathrm{T}_{4}$ were compared by use of the unpaired $t$-test. The measured values of TSH were log-transformed and compared using analysis of variance. To compare the prevalence of thyroiditis between the experimental groups and the control group the $\chi^{2}$-test was used for the combined groups of male and female rats, whereas Fisher's exact $t$-test was used to compare the separate groups of male and female rats because of the lower number of rats in each group. The degree of thyroiditis was compared in the animals with histological signs of thyroiditis 

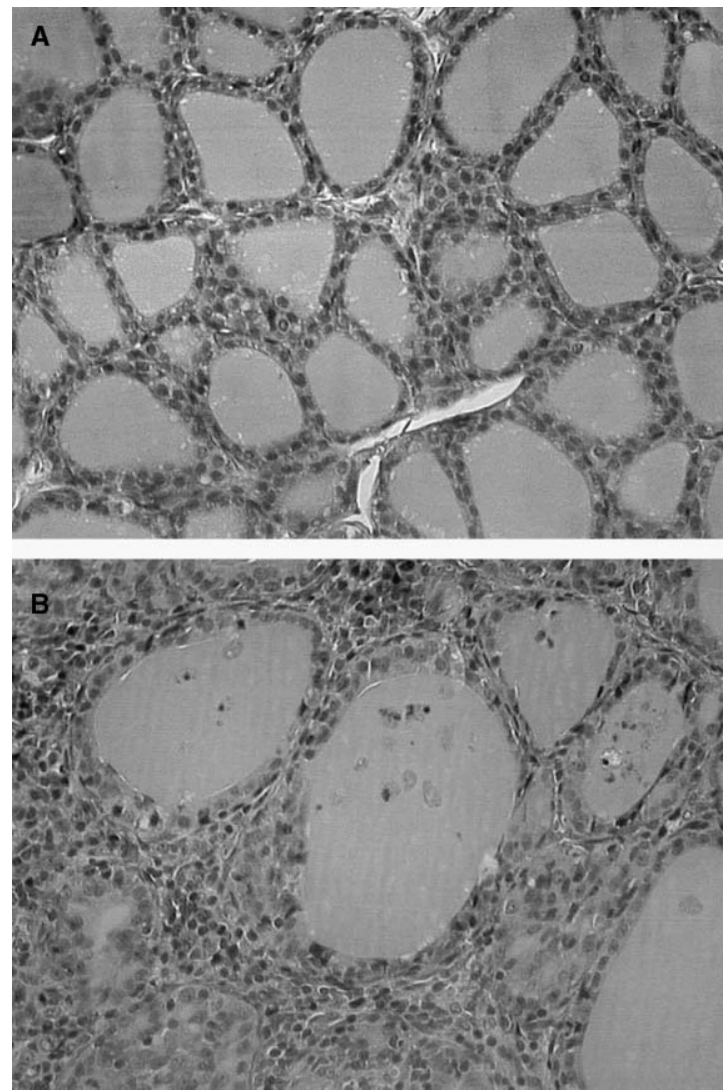

Figure 2 Thyroid glands from BB rats at the age of 19 weeks. (A) Normal thyroid gland. (B) Thyroid gland with lymphocytic infiltration. This gland was scored 4 , more than $50 \%$ histological alteration related to the tissue area without knowledge of eventual tissue shrinkage. The final magnification was 620 .

using Mann-Whitney's test. Analysis of variance was applied to compare the body weights of the adult BB rats and unpaired $t$-test was used to compare the body weights of Wistar rats. In respect of the prevalence and degree of AIT and body weight of the adult BB rats the control groups were homogenous and were combined to serve as one control group $(n=82)$.
The prevalence and degree of AIT as well as the body weight were significantly different between males and females in most of the groups. Consequently all analyses were also done separately for the two sexes. Differences were considered to be significant when $P<0.05$.

\section{Results}

\section{Neonatal treatment with NaI}

$\mathrm{NaI}$ given immediately post partum and daily for the first 6 days reduced the prevalence of AIT to $32 \pm 9 \%$ (mean \pm S.E.M.) compared with $66 \pm 5 \%$ in the control animals $(P<0.002)$ (Table 1$)$. This reduction was mainly accounted for by female rats the prevalence of whom was reduced to $13 \pm 9 \%$ compared with $52 \pm 8 \%$ in the control group $(P<0.006)$. No difference was found for the group of male rats $(53 \pm 1$ vs $80 \pm 6, P=0.054)$. No differences in the degree of thyroiditis were found among the affected animals (Table 1).

\section{Neonatal stimulation by TSH}

Neonatal stimulation by TSH given immediately post partum and for the first 3 days in the first 3 weeks did not change the prevalence or degree of AIT compared with the control group (Table 1).

\section{Adolescent suppression with $\boldsymbol{T}_{3}$}

Suppression of the thyroid gland during adolescence by $\mathrm{T}_{3}$ administered daily in the drinking water had a biphasic response (Table 1). Treatment from the age of 3 to 9 weeks reduced the prevalence to less than one fourth of the prevalence in the control group $\left(14 \pm 7\right.$ vs $\left.66 \pm 5 \%, P<10^{-5}\right)$. This more than halved the prevalence of AIT to $29 \pm 13 \%$ for the group of male rats compared with $80 \pm 6 \%$ in the control group $(P<0.001)$ whereas for female rats AIT was completely eliminated $(0 \pm 0 \%)$ while it was present

Table 1 Prevalence and degree (graduated from 0-4) of thyroiditis (AIT) in BB rats at the age of 19 weeks after neonatal stimulation with $\mathrm{Nal}$ or $\mathrm{TSH}$ or adolescent suppression with $\mathrm{T}_{3}$.

\begin{tabular}{|c|c|c|c|c|c|c|}
\hline \multirow[b]{2}{*}{ Treatment } & & \multicolumn{3}{|c|}{$\begin{array}{l}\text { Prevalence in percent } \\
\quad(\text { mean } \pm \text { S.E.M. })(n)\end{array}$} & \multicolumn{2}{|c|}{$\begin{array}{l}\text { Degree of thyroiditis } \\
(\text { mean } \pm \text { S.E.M.) }(n)\end{array}$} \\
\hline & & All & Males & Females & Males & Females \\
\hline Control group & & $66 \pm 5(82)$ & $80 \pm 6(40)$ & $52 \pm 8(42)$ & $1.6 \pm 0.1(32)$ & $1.5 \pm 0.2(22)$ \\
\hline \multirow[t]{2}{*}{ Neonatal stimulation } & Nal & $32 \pm 9(31)+$ & $53 \pm 13(15) \#$ & $13 \pm 9(16)^{\star}$ & $2.1 \pm 0.4(8)$ & $1.0 \pm 0.0(2)$ \\
\hline & TSH & $63 \pm 9(32)$ & $80 \pm 9(20)$ & $35 \pm 14(12)$ & $1.8 \pm 0.2(16)$ & $1.8 \pm 0.8(4)$ \\
\hline \multirow[t]{2}{*}{ Adolescent suppression } & $\mathrm{T}_{3}^{\mathrm{a}}$ & $14 \pm 7(28)++$ & $29 \pm 13$ (14)\#\# & $0(14)^{\star \star}$ & $1.3 \pm 0.3(4)$ & $-(0)$ \\
\hline & $T_{3}^{b}$ & $81 \pm 7(36)$ & $85 \pm 10(13)$ & $78 \pm 9(23)^{\star \star \star}$ & $1.4 \pm 0.2(11)$ & $1.4 \pm 0.2(18)$ \\
\hline
\end{tabular}

Nal was given for the first 6 days post partum and TSH for the first 3 days in the first 3 weeks post partum. $T_{3}$ was given from the age of ${ }^{\text {a }} 3$ to 9 weeks or ${ }^{b_{5}} 5$ to 9 weeks. The degree of thyroiditis in BB rats at the age of 19 weeks was scored from 0 to 4 in animals positive for thyroiditis. All the treated groups were compared with the corresponding control group. The combined groups of male and female rats were compared with the control group by Chi-square test: $+P<0.002,++P=2.4 \times 10^{-6}$, the groups of male and female rats taken separately were compared with the corresponding control group by Fisher's exact $t$-test; $\# P=0.053, \# \# P<0.001$, ${ }^{\star} P<0.006,{ }^{* \star} P<0.0003$ and ${ }^{\star \star \star} P<0.035$. 
in $52 \pm 8 \%$ of the female control group $(P<0.0003)$. No changes in the degree of thyroiditis were seen (Table 1).

Conversely, treatment of female rats with $\mathrm{T}_{3}$ from the age of 5 to 9 weeks increased the prevalence of AIT to $78 \pm 9 \%$ compared with $52 \pm 8 \%$ in the control group $(P=0.035)$ (Table 1). For the combined group of male and female rats and for the group of male rats only the tendency was the same although the differences were not significant.

Adolescent suppression by $\mathrm{T}_{3}$ did not change the degree of AIT. None of the Wistar rats developed AIT.

\section{Body weight}

The weight of the $\mathrm{BB}$ rats at the time of death (19 weeks) was not affected by the different treatments (Table 2) or the presence of thyroiditis (data not shown).

\section{Serum levels of TSH}

Serum levels of TSH, measured in six male rats with and six male rats without AIT from each group of BB rats at the time of death at 19 weeks old, were identical in all the groups (Table 2).

Despite the loss of weight of the Wistar rats killed just after the end of $T_{3}$ treatment, none of the rats showed any clinical signs of hyper- or hypothyroidism.

\section{Discussion}

In a spontaneous animal model of AIT, the influence of the development of AIT by neonatal stimulation with $\mathrm{NaI}$ and TSH and adolescent suppression with $\mathrm{T}_{3}$ was examined. Neonatal treatment with iodine was found to reduce the prevalence of thyroiditis particularly in female BB rats, which to our knowledge has not been described before. By contrast, it is well known that iodine given in excess in adult life usually provokes development of AIT in several species including humans and rats (18). Acute changes in iodine intake seem to be especially important $(19,20)$. The reduced prevalence of thyroiditis found in this study is in line with the results of two other studies, Buschard et al. (12) and Bock et al. (11), who similarly found that the incidence of diabetes was reduced after neonatal stimulation of the $\beta$-cells by arginine and/or glucose in both BB rats and NOD mice. The theoretical explanation for the reduced prevalence of AIT following neonatal stimulation is suggested to be the formation of a strong 'self' and induction of immunotolerance due to early increased organ activity and exposure of organ-specific antigens to the immune system. In this connection thyroglobulin $(\mathrm{Tg})$ could be an interesting antigen, since highly iodinated $\mathrm{Tg}$ is found to be highly antigenic in adult rats and chickens $(21,22)$ and thus an early iodination of Tg may induce tolerance instead.

Neonatal stimulation with TSH did not reduce the prevalence of AIT. TSH was given during a period when the gland is susceptible to TSH (15) so the different outcome compared with iodine treatment is peculiar and without obvious explanation. In the evaluation of the effect of TSH on thyroid function it failed to change serum $\mathrm{T}_{4}$ concentrations. Although speculative, this could be due to a relative iodine deficiency resulting in a shift to $\mathrm{T}_{3}$ production or a rebound effect because the effect of TSH is much faster and the maximum response in serum $\mathrm{T}_{4}$ concentration is found already $2-3 \mathrm{~h}$ after TSH administration (15). Finally, TSH is secreted in a pulsatile manner and consequently administration only once a day may not be enough to stimulate the gland sufficiently (23). Experimentally, it has previously been shown that TSH increased the expression of thyroperoxidase (TPO) on the surface of human thyrocytes in vitro with an over-representation of epitopes recognized by autoantibodies against TPO (24), and thyroid

Table 2 Characteristics of BB rats at the time of death (19 weeks old) after neonatal stimulation by Nal or TSH or after adolescent suppression by $T_{3}$.

\begin{tabular}{|c|c|c|c|c|c|}
\hline \multirow[b]{2}{*}{ Treatment } & & \multicolumn{2}{|c|}{ 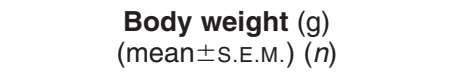 } & \multicolumn{2}{|c|}{$\begin{array}{c}\text { TSH }(\mathrm{mU} / \mathrm{l}) \\
\text { (median and range) }(n=6)\end{array}$} \\
\hline & & Males & Females & With thyroiditis & Without thyroiditis \\
\hline Control group & & $452 \pm 7(40)$ & $255 \pm 4(41)$ & $3.2(3.0-4.7)$ & $2.9(2.3-4.0)$ \\
\hline \multirow[t]{2}{*}{ Neonatal stimulation } & $\mathrm{Nal}$ & $448 \pm 111(14)$ & $262 \pm 6(16)$ & $3.0(2.5-5.0)$ & $3.0(2.5-3.2)$ \\
\hline & TSH & $431 \pm 9(19)$ & $256 \pm 7(11)$ & $\mathrm{Nd}$ & $\mathrm{Nd}$ \\
\hline \multirow[t]{2}{*}{ Adolescent suppression } & $\mathrm{T}_{3}^{\mathrm{a}}$ & $425 \pm 11(14)$ & $261 \pm 7(14)$ & $3.4(2.0-4.3)$ & $3.1(2.4-5.3)$ \\
\hline & $\mathrm{T}_{3}^{\mathrm{b}}$ & $436 \pm 12(13)$ & $260 \pm 5(22)$ & $2.8(2.3-7.9)$ & $3.3(1.9-7.7)$ \\
\hline
\end{tabular}

Nal was given for the first 6 days post partum and TSH for the first 3 days in the first 3 weeks post partum. T was given from the age of ${ }_{3} 3$ to 9 weeks or ${ }^{\mathrm{b}} 5$ to 9 weeks. The body weights of the BB rats in all treated groups were compared with the corresponding control group by use of analysis of variance and finally the groups of rats with thyroiditis were combined with the groups of rats without thyroiditis (data not shown). Serum values of TSH were measured in six randomly selected male rats with and six without thyroiditis from each group of BB rats at death (19 weeks) and the log-transformed values were compared with the control groups. No statistical significances were found.

$\mathrm{Nd}$, not done. 
microsomal antigen expression on the surface of Fischer Rat Thyroid cell Line 5 cells has been found to be stimulated by TSH (25).

During adolescence, early suppression of the thyroid gland by $\mathrm{T}_{3}$ decreased the prevalence of AIT in BB rats. In female rats, the thyroiditis was completely prevented and in male rats the prevalence was more than halved. Just after the end of $\mathrm{T}_{3}$ treatment TSH was suppressed compared with the control group and was just below the normal range of the assay. This, together with a reduced body weight, might indicate a mild thyrotoxicosis although the rats were not otherwise clinically thyrotoxic and TSH was normalized 3 weeks after the end of treatment. In keeping with our study, the preventive effect of $\mathrm{T}_{3}$ on the incidence of thyroiditis has been described in previous studies in spontaneous and induced AIT in rats $(26-28)$ and hypothyroid cats (29) where the incidence, severity and level of antibodies were found to be reduced after treatment with $\mathrm{T}_{4}$. In these previous studies, $\mathrm{T}_{4}$ and not $\mathrm{T}_{3}$ was used and it was administered in supraphysiological doses and for periods of up to 3 months $(26-28)$. Only in one previous study was no effect of $\mathrm{T}_{4}$ on the prevalence of AIT found (30). Our finding also parallels studies in type 1 diabetes in which a lower $\beta$-cell activity after insulin treatment of $\mathrm{BB}$ rats in adolescence was found to reduce the incidence of diabetes (13). A recent study has found a preventive effect of insulin treatment on the progressive $\beta$-cell failure in slowly progressive T1DM in a Japanese population (31).

The underlying mechanism of action has yet to be determined but a possible mechanism could include an induction of thyroid cell rest, and due to this rest a reduced antigen expression on the thyrocytes and less risk of autoimmune aggression in parallel with the described mechanism for the reduced diabetes incidence $(5,32,33)$. Break of tolerance might be more difficult if the antigens are weakly exposed. In addition, the resting $\beta$-cell is found to be less vulnerable to interleukin $1 \beta$-mediated impairment (7).

Furthermore, we found that late adolescent suppression of the thyroid gland by $\mathrm{T}_{3}$ increased the prevalence of AIT in female BB rats. This effect of thyroid hormones has not, to our knowledge, been shown before and seems to be closely related to the time window of the treatment. A possible mechanism behind this effect of $\mathrm{T}_{3}$ could be stimulation of an already ongoing immune process at this age. The biphasic time-dependent effect of $\mathrm{T}_{3}$ on the prevalence of thyroiditis may reflect the dilemma of whether or not treatment with thyroid hormones might enhance an ongoing immune process of human autoimmune thyroiditis $(9,10)$.

It is unknown whether the biphasic effect of $\mathrm{T}_{3}$ on AIT is due to the start-point of treatment or the different duration of treatment (in this case 4 and 6 weeks respectively). If duration of treatment is the important cause, differences in maturation of the endocrine system, sexual development or the immune system itself could be the explanation. For the importance of start-point as a crucial factor, it has been found that complete removal of thymic tissue by thymectomy at the age of 5 weeks and irradiation after 2 weeks in Wistar rats increased the incidence of thyroiditis (34) and reconstitution with normal lymphoid cells restored the animals (35). However, timing in reconstitution was also crucial since only early reconstitution could abrogate the autoimmunity while later reconstitution had no effect (35). Although these experiments are different from ours they may provide a possible explanation for the difference in response to $T_{3}$ found in early and late adolescence where thymic maturity might be the key. This will need to be clarified by further study.

We found that after neonatal treatment by $\mathrm{NaI}$ and early $\mathrm{T}_{3}$ administration female rats were better protected against thyroiditis than male rats and were more affected after later $\mathrm{T}_{3}$ administration. Usually females are affected more often than males by autoimmune diseases which is also found in experimental models of AIT in rats (36). Loci on the X chromosome seem to be of importance in the pathogenesis of Graves' disease which could be related to the female preponderance (37-41). The lack of female preponderance in the control group has also been described by others (42) and could be due to inbreeding of the rats and thus increased influence of the genetic factor in disease development (43) or it could be due to a stronger genetic influence in animals with polyendocrine diseases where the environmental influence, in this case the sex hormones, may disappear (44). In this study we found that the different treatments changed the prevalence of thyroiditis but not the degree of lymphocytic infiltration and tissue destruction. These results are original and we can still only speculate on the possible mechanisms. The histological grading of the lesions is semi-quantitative and able to detect significant differences in prevalence. It is not yet known how the degree of tissue destruction correlates to the clinical and biochemical disease manifestations. We did not measure anti-Tg antibodies in these rats but previous studies have found that the presence and the level of anti-Tg antibodies correlate with the presence of AIT in both spontaneous and induced rat models of AIT also after $\mathrm{T}_{4}$ treatment $(16,18,28,45,46)$ although one study found no difference after $\mathrm{T}_{4}$ treatment (27) and another study could not find a correlation between the degree of AIT and the level of anti-Tg antibodies after induction of AIT by iodinated Tg (21).

In conclusion, neonatal stimulation of the thyroid gland with iodine as well as early adolescent suppression with $\mathrm{T}_{3}$ reduced the prevalence of AIT in BB rats, whereas $\mathrm{T}_{3}$ administered later increased the prevalence. Our results indicate that thyroid activity at various ages of development seems to influence the development of autoimmune thyroid diseases. 


\section{Acknowledgements}

This work was supported by a fellowship to MarieLouise Hartoft-Nielsen by The National University Hospital of Copenhagen and support by the Foundation of Director Jacob Madsen and wife Olga Madsen and the Foundation of Agnes and Knut Mørk.

The excellent technical assistance of Margit Bæksted, Jette Pedersen, Pernille Albrectsen and Birthe Nielsen and the expert statistical assistance of Dr Åge Vølund are gratefully acknowledged. Insulatard was a present from M D Klavs Jørgensen.

\section{References}

1 Rotella CM, Dotta F, Mannucci E \& Di Mario U. Autoantigens in thyroid and islet autoimmunity: similarities and differences. Autoimmunity 199212 223-237.

2 Weetman AP. Autoimmune thyroid disease: propagation and progression. European Journal of Endocrinology 2003148 1-9.

3 Sternthal E, Like AA, Sarantis K \& Braverman LE. Lymphocytic thyroiditis and diabetes in the $\mathrm{BB} / \mathrm{W}$ rat. A new model of autoimmune endocrinopathy. Diabetes 198130 1058-1061.

4 Rajatanavin R, Appel MC, Reinhardt W, Alex S, Yang YN \& Braverman LE. Variable prevalence of lymphocytic thyroiditis among diabetes-prone sublines of $\mathrm{BB} / \mathrm{W}$ rats. Endocrinology 1991128 153-157.

5 Buschard K, Brogren CH, Ropke C \& Rygaard J. Antigen expression of the pancreatic beta-cells is dependent on their functional state, as shown by a specific, BB rat monoclonal autoantibody IC2. Acta Pathologica Microbiologica et Immunologica Scandinavia $198896342-346$.

6 Kampe O, Andersson A, Bjork E, Hallberg A \& Karlsson FA. Highglucose stimulation of $64000-\mathrm{Mr}$ islet cell autoantigen expression. Diabetes 198938 1326-1328.

7 Palmer JP, Helqvist S, Spinas GA, Molvig J, Mandrup-Poulsen T, Andersen HU \& Nerup J. Interaction of beta-cell activity and IL-1 concentration and exposure time in isolated rat islets of Langerhans. Diabetes 198938 1211-1216.

8 Weetman AP \& McGregor AM. Autoimmune thyroid disease: further developments in our understanding. Endocrine Reviews $199415788-830$.

9 Hashizume K, Ichikawa K, Sakurai A, Suzuki S, Takeda T, Kobayashi M, Miyamoto T, Arai M \& Nagasawa T. Administration of thyroxine in treated Graves' disease. Effects on the level of antibodies to thyroid-stimulating hormone receptors and on the risk of recurrence of hyperthyroidism. New England Journal of Medicine $1991324947-953$.

10 Rieu M, Richard A, Rosilio M, Laplanche S, Ropion V, Fombeur JP \& Berrod JL. Effects of thyroid status on thyroid autoimmunity expression in euthyroid and hypothyroid patients with Hashimoto's thyroiditis. Clinical Endocrinology $1994 \mathbf{4 0} 529-535$.

11 Bock T, Kjaer TW, Jorgensen M, Josefsen K, Rygaard J \& Buschard $\mathrm{K}$. Reduction of diabetes incidence in NOD mice by neonatal glucose treatment. Acta Pathologica Microbiologica et Immunologica Scandinavia $199199989-992$.

12 Buschard K, Jorgensen M, Aaen K, Bock T \& Josefsen K. Prevention of diabetes mellitus in BB rats by neonatal stimulation of beta cells. Lancet $1990335134-135$.

13 Gotfredsen CF, Buschard K \& Frandsen EK. Reduction of diabetes incidence of BB Wistar rats by early prophylactic insulin treatment of diabetes-prone animals. Diabetologia 198528 933-935.

14 Dussault JH \& Labrie F. Development of the hypothalamic-pituitary-thyroid axis in the neonatal rat. Endocrinology 197597 $1321-1324$

15 Oberkotter LV. Developmental changes in rat thyroid responsiveness to thyrotropin administered by the subcutaneous and peroral route. Proceedings of The Society for Experimental Biology and Medicine 1988187 360-365.

16 Braverman LE, Paul T, Reinhardt W, Appel MC \& Allen EM. Effect of iodine intake and methimazole on lymphocytic thyroiditis in the BB/W rat. Acta Endocrinologica 1987281 70-76.

17 Colzani RM, Alex S, Dunn AD, Dunn JT, Stone S \& Braverman LE. The oral administration of human thyroglobulin does not affect the incidence of lymphocytic thyroiditis in the biobreeding Worcester rat. Thyroid $1999 \mathbf{9} 831-835$.

18 Allen EM, Appel MC \& Braverman LE. The effect of iodide ingestion on the development of spontaneous lymphocytic thyroiditis in the diabetes-prone $\mathrm{BB} / \mathrm{W}$ rat. Endocrinology $1986 \mathbf{1 1 8}$ 1977-1981.

19 Kahaly GJ, Dienes HP, Beyer J \& Hommel G. Iodide induces thyroid autoimmunity in patients with endemic goitre: a randomised, double-blind, placebo-controlled trial. European Journal of Endocrinology $1998139290-297$.

20 Tsatsoulis A, Johnson EO, Andricula M, Kalogera C, Svarna E, Spyroy P, Seferiadis K \& Tsolas O. Thyroid autoimmunity is associated with higher urinary iodine concentrations in an iodine-deficient area of Northwestern Greece. Thyroid 19999 279-283.

21 Ebner SA, Lueprasitsakul W, Alex S, Fang SL, Appel MC \& Braverman LE. Iodine content of rat thyroglobulin affects its antigenicity in inducing lymphocytic thyroiditis in the BB/Wor rat. Autoimmunity $199213209-214$.

22 Sundick RS, Herdegen DM, Brown TR \& Bagchi N. The incorporation of dietary iodine into thyroglobulin increases its immunogenicity. Endocrinology $1987 \mathbf{1 2 0} 2078-2084$.

23 Leitolf H, Szkudlinski MW, Hoang-Vu C, Thotakura NR, von zur Muhlen A, Brabant G \& Weintraub BD. Effects of continuous and pulsatile administration of pituitary rat thyrotropin and recombinant human thyrotropin in a chronically cannulated rat. Hormone and Metabolic Research 199527 173-178.

24 Rasmussen AK, Feldt-Rasmussen U, Brandt M, Hartoft-Nielsen ML, Carayon P \& Buschard K. Thyrotropin stimulates specifically the expression of the autoantibody binding domains of the thyroperoxidase molecule. Autoimmunity 199929 323-331.

25 Chiovato L, Vitti P, Lombardi A, Kohn LD \& Pinchera A. Expression of the microsomal antigen on the surface of continuously cultured rat thyroid cells is modulated by thyrotropin. Journal of Clinical Endocrinology and Metabolism 198561 $12-16$.

26 Banovac K, Ghandur-Mnaymneh L, Zakarija M, Rabinovitch A \& McKenzie JM. The effect of thyroxine on spontaneous thyroiditis in BB/W rats. International Archives of Allergy and Applied Immunology $1988 \mathbf{8 7} 301-305$.

27 Hassman R, Weetman AP, Gunn C, Stringer BM, WynfordThomas D, Hall R \& McGregor AM. The effects of hyperthyroidism on experimental autoimmune thyroiditis in the rat. Endocrinology $19851161253-1258$.

28 Reinhardt W, Paul TL, Allen EM, Alex S, Yang YN, Appel MC \& Braverman LE. Effect of L-thyroxine administration on the incidence of iodine induced and spontaneous lymphocytic thyroiditis in the BB/Wor rat. Endocrinology 1988122 1179-1181.

29 Schumm-Draeger PM, Langer F, Caspar G, Rippegather K, Herrmann G, Fortmeyer HP, Usadel KH \& Hubner K. Spontaneous Hashimoto-like thyroiditis in cats. Verhandlungen der Deutsche Geseltshaft fur Pathologie $1996 \mathbf{8 0} 297-301$.

30 Weetman AP, McGregor AM, Rennie DP \& Hall R. Thyroid hormones fail to influence experimental autoimmune thyroiditis. Clinical and Experimental Immunology 198250 51-54.

31 Maruyama T, Shimada A, Kanatsuka A, Kasuga A, Takei I, Yokoyama J \& Kobayashi T. Multicenter prevention trial of slowly progressive type 1 diabetes with small dose of insulin (the Tokyo study): preliminary report. Annals of the New York Academy of Sciences $2003 \mathbf{1 0 0 5} 362-369$.

32 Aaen K, Rygaard J, Josefsen K, Petersen H, Brogren CH, Horn T \& Buschard K. Dependence of antigen expression on functional state of beta-cells. Diabetes $199039697-701$. 
33 Buschard K. The functional state of the beta cells in the pathogenesis of insulin-dependent diabetes mellitus. Autoimmunity 1991 10 65-69.

34 Penhale WJ, Farmer A, McKenna RP \& Irvine WJ. Spontaneous thyroiditis in thymectomized and irradiated Wistar rats. Clinical and Experimental Immunology 197315 225-236.

35 Penhale WJ, Irvine WJ, Inglis JR \& Farmer A. Thyroiditis in T cell-depleted rats: suppression of the autoallergic response by reconstitution with normal lymphoid cells. Clinical and Experimental Immunology 197625 6-16.

36 Penhale WJ, Farmer A, Urbaniak SJ \& Irvine WJ. Susceptibility of inbred rat strains to experimental thyroiditis: quantitation of thyroglobulin-binding cells and assessment of T-cell function in susceptible and non-susceptible strains. Clinical and Experimental Immunology $197519179-191$.

37 Barbesino G, Tomer Y, Concepcion ES, Davies TF \& Greenberg DA. Linkage analysis of candidate genes in autoimmune thyroid disease. II. Selected gender-related genes and the X-chromosome. International Consortium for the Genetics of Autoimmune Thyroid Disease. Journal of Clinical Endocrinology and Metabolism $1998833290-3295$.

38 Tomer Y. Anti-thyroglobulin autoantibodies in autoimmune thyroid diseases: cross-reactive or pathogenic? Clinical Immunology and Immunopathology 199782 3-11.

39 Ansar AS, Young PR \& Penhale WJ. The effects of female sex steroids on the development of autoimmune thyroiditis in thymectomized and irradiated rats. Clinical and Experimental Immunology $1983 \mathbf{5 4} 351-358$.
40 Ansar AS, Young PR \& Penhale WJ. Beneficial effect of testosterone in the treatment of chronic autoimmune thyroiditis in rats. Journal of Immunology 1986136 143-147.

41 Estienne V, Duthoit C, Reichert M, Praetor A, Carayon P, Hunziker W \& Ruf J. Androgen-dependent expression of FcgammaRIIB2 by thyrocytes from patients with autoimmune Graves' disease: a possible molecular clue for sex dependence of autoimmune disease. FASEB Journal 200216 1087-1092.

42 Awata T, Guberski DL \& Like AA. Genetics of the BB rat: association of autoimmune disorders (diabetes, insulitis, and thyroiditis) with lymphopenia and major histocompatibility complex class II. Endocrinology $19951365731-5735$.

43 Polley CR, Bacon LD \& Rose NR. Spontaneous autoimmune thyroiditis in chickens. I. Effects of bursal reconstitution. Journal of Immunology 1981127 1465-1468.

44 Ottesen M, Feldt-Rasmussen U, Andersen J, Hippe E \& Schouboe A. Thyroid function and autoimmunity in pernicious anemia before and during cyanocobalamin treatment. Journal of Endocrinological Investigations $1995 \mathbf{1 8} 91-97$.

45 Allen EM, Appel MC \& Braverman LE. Iodine-induced thyroiditis and hypothyroidism in the hemithyroidectomized $\mathrm{BB} / \mathrm{W}$ rat. Endocrinology $1987121481-485$.

46 Lueprasitsakul W, Alex S, Fang SL, Appel MC \& Braverman LE. Thyroglobulin induced lymphocytic thyroiditis in two sublines of BB/Wor rats. Autoimmunity 19919 55-60.

Received 14 March 2004

Accepted 16 June 2004 